\title{
Household Air Pollution and Respiratory Health in Rural Crete, Greece: A Cross-Sectional FRESH AIR Study
}

\author{
Marilena Anastasaki ${ }^{1, *}$, Ioanna Tsiligianni ${ }^{1}$, Dimitra Sifaki-Pistolla ${ }^{1}$, Vasiliki Eirini Chatzea ${ }^{1}$, Andreas Karelis ${ }^{1}$, \\ Antonios Bertsias ${ }^{1}$, Niels H. Chavannes ${ }^{2}{ }^{\mathbb{D}}$, Frederik van Gemert ${ }^{3}$, Christos Lionis ${ }^{1}$ \\ and the FRESH AIR Collaborators ${ }^{\dagger}$
}

check for updates

Citation: Anastasaki, M.; Tsiligianni, I.; Sifaki-Pistolla, D.; Chatzea, V.E.; Karelis, A.; Bertsias, A.; Chavannes, N.H.; van Gemert, F.; Lionis, C.; the FRESH AIR Collaborators.

Household Air Pollution and Respiratory Health in Rural Crete, Greece: A Cross-Sectional FRESH AIR Study. Atmosphere 2021, 12, 1369. https://doi.org/10.3390/atmos12111369

Academic Editors: Aikaterini

Bougiatioti and Despina

Paraskevopoulou

Received: 29 June 2021

Accepted: 5 October 2021

Published: 20 October 2021

Publisher's Note: MDPI stays neutral with regard to jurisdictional claims in published maps and institutional affiliations.

Copyright: (c) 2021 by the authors. Licensee MDPI, Basel, Switzerland. This article is an open access article distributed under the terms and conditions of the Creative Commons Attribution (CC BY) license (https:/ / creativecommons.org/licenses/by/ $4.0 /)$.
1 Clinic of Social and Family Medicine, School of Medicine, University of Crete, 71003 Heraklion, Greece; i.tsiligianni@uoc.gr (I.T.); spdimi11@gmail.com (D.S.-P.); valchatz@hotmail.com (V.E.C.); a.karelis@med.uoc.gr (A.K.); antonisbertsias@yahoo.gr (A.B.); lionis@galinos.med.uoc.gr (C.L.)

2 Department of Public Health and Primary Care, Leiden University Medical Center, 2333 ZA Leiden, The Netherlands; n.h.chavannes@lumc.nl

3 Department of General Practice and Elderly Care, Groningen Research Institute for Asthma and COPD (GRIAC), University Medical Center Groningen, 9713 EZ Groningen, The Netherlands; frgemert@xs4all.nl

* Correspondence: anastasakimarilena@yahoo.gr; Tel.: +30-2810-394613; Fax: +30-2810-394861

+ It indicates the collaborators of the overall Horizon 2020 project that this study belongs.

Abstract: Breathing polluted air is a risk to respiratory conditions. During the Greek financial crisis, the use of household fireplaces/wood stoves shifted from mostly decorative to actual domestic heating, resulting in increased indoor smoke production. We aimed to evaluate household air pollution (HAP), fuel use and respiratory symptoms in rural Crete, Greece. $\mathrm{PM}_{2.5}$ and $\mathrm{CO}$ were measured in 32 purposively selected rural households (cross-sectional study) at periods reflecting lesser (baseline) versus extensive (follow-up) heating. Clinical outcomes were assessed using questionnaires. Mean $\mathrm{PM}_{2.5}$ were not significantly different between measurements $\left(36.34 \mu \mathrm{g} / \mathrm{m}^{3} \mathrm{vs} .54 .38 \mu \mathrm{g} / \mathrm{m}^{3}, p=0.60\right)$ but exceeded the WHO air quality guidelines. Mean and maximal CO levels were below the WHO cut-offs (0.56 ppm vs. 0.34 ppm, $p=0.414$ and 26.1 ppm vs. 9.72 ppm, $p=0.007$, respectively). In total, $90.6 \%$ of households were using wood stoves or fireplaces for heating, but half also owned clean fuel devices. The differences between devices that were owned versus those that were used were attributed to financial reasons. In both cases, the most frequent respiratory symptoms were phlegm $(27.3 \%$ vs. $15.2 \% ; p=0.34)$ and cough $(24.2 \%$ vs. $12.1 \% ; p=0.22)$. Our findings demonstrate the magnitude of HAP and confirm the return to harmful practices during Greece's austerity. Upon validation, these results can support strategies for fighting fuel poverty, empowering communities and strengthening local health systems.

Keywords: household air pollution; $\mathrm{PM}_{2.5}$; $\mathrm{CO}$; respiratory health; fuel poverty; economic crisis; Greece

\section{Introduction}

Breathing polluted air is a risk factor to most respiratory conditions [1]. Improving air quality and reducing exposure to any kind of smoke are important steps towards promoting respiratory health [2]. In many low-resource settings, however, smoke produced by burning biomass inside households for heating and/or cooking is an important source of household air pollution (HAP) [3], the levels of which may often exceed the internationally established air quality standards $[4,5]$.

In such settings, indoor biomass burning is mainly attributed to financial and awareness reasons, which impede the availability and purchase of clean fuels and the adoption of preventive measures [6]. Yet, accumulating evidence suggests that exposure to HAP can substantially increase the burden and risk of chronic obstructive pulmonary disease (COPD) and can affect lung health in childhood [7-10]. Specifically for Greece, about 
1838 deaths and 31,611 disability-adjusted life years (DALYs) have been attributed to HAP (age-standardized rates of deaths and DALYs per 100,000 capita: 6 and 136.7, respectively) [11]. Worldwide, biomass fuels are approximately used by $50 \%$ of households, exposing more than three billion people to the adverse effects of indoor air pollution [4].

In Greece, the issue of air quality deterioration received prominence during the peak of the recent financial crisis, which substantially affected the country. Outdoor air quality data from urban settings suggested a dramatic rise in the concentration of airborne particulate matters during the winter period, which, apart from morning traffic hours, also peaked at noon [12-14]. Additionally, measurements of carbon monoxide during the night time suggested that emissions from biomass combustion contributed increasingly to the atmospheric pollution of urban areas [15]. The phenomenon was attributed to an increased use of fireplaces which, due to the significant increases in the price of conventionally-used fuel oil, shifted from mostly decorative reasons to actual domestic heating [16,17]. A survey of 598 Greek households showcased the impact of the economic crisis on energy consumption, highlighting that low-income households were even more vulnerable to being "fuel poor" [18].

Comparative figures demonstrate that biomass fuel use in Greece has increased between the pre- and post-financial recession periods. Namely, in 2005, slightly more than $2 \%$ of the total energy use in the household sector was attributed to biomass burning. In 2030 , it is estimated that the respective share will reach almost $4 \%$. These estimates exceed the European Unions' overall use, where, in 2005, biomass combustion in the residential sector accounted for $1.9 \%$ of total energy use, while the respective estimate for 2030 is approximately $3 \%$ [19].

Despite the above evidence, little is known about the magnitude and health effects of HAP in Greek households. Data are even scarcer for rural areas, which, despite being more deprived than urban areas, have been equally affected by austerity [20]. Households in Greek remote and mountainous areas are even more prone to fuel poverty than urban areas due to their increased heating needs, accessibility and economic restrictions [21]. The economic recession also seems to have had a particular impact on disease management for patients with chronic respiratory diseases [22], as well as on the general respiratory health of the rural population of Crete [23].

This study aims to assess HAP levels, heating activity and residents' respiratory symptoms and awareness between periods of differing biomass use intensity in rural Crete, Greece, to reflect on the generalized impact of the country's economic recession on health-related practices and outcomes.

\section{Methods}

\subsection{Design, Setting and Participants}

A cross-sectional study was conducted as part of the European, Horizon 2020 programme "FRESH AIR" [24]. In eight purposively selected rural and remote villages in the county of Heraklion, Crete, Greece, households using biomass fuels for heating were identified for the measurement of indoor air pollution. In each house, a household survey was completed by the person most responsible for domestic issues and an individual questionnaire was administered to all adult residents. Both tools included a combination of open- and closed-ended questions and were administered by the researchers to the participants during a face-to-face interview.

\subsection{Environmental Outcomes}

Environmental outcomes of HAP were assessed by measuring carbon monoxide (CO) and particulate matter smaller than $2.5 \mu \mathrm{g}\left(\mathrm{PM}_{2.5}\right)$. Measurements were conducted by trained researchers who visited the participating households at two time points reflecting periods of lesser (baseline: November-December 2017) versus extensive heating (follow-up: January-March 2018). Normally, these periods should reflect the verge of change between the seasons that influence the intensity of fuel use. $\mathrm{CO}$ and $\mathrm{PM}_{2.5}$ levels were recorded 
for $48 \mathrm{~h}$ each time. A stationary monitoring was performed. Namely, researchers visited households and placed the $\mathrm{CO}$ and $\mathrm{PM}_{2.5}$ monitors above the central fireplace/stove, usually located in the central living room or kitchen. Researchers returned two days later to collect the monitors. Both at baseline and follow-up, all households of the same village were generally measured simultaneously, although measurements between different villages were performed on different days (due to a limited number of monitors available for this study). In cases where fast monitor battery discharge was identified during the monitor collection visit, the measurement was repeated on another day.

\section{3. $\mathrm{PM}_{2.5}$ Monitoring}

$\mathrm{PM}_{2.5}$ levels were measured using the RTI MicroPEM Sensor (https: / / www.rti.org/ impact/micropem-sensor-measuring-exposure-air-pollution, accessed on 1 October 2021). The MicroPEM provides fully representative personal exposure characterizations by simultaneously defining the integrated exposure (filter based) as well as the patterns of exposure (real-time) in a wearable, lightweight, quiet, low-burden monitor. Due to limitations in device availability, in this study, the MicroPEM was placed above the central fireplace/stove of the household rather than worn personally. The MicroPEM collects up to 500 micrograms of PM on a $25 \mathrm{~mm}$ PTFE filter for gravimetric and speciation analyses. The laser-based light scattering nephelometer collects real-time PM concentration data at up to $3 \mathrm{~s}$ resolution over a range from 3 to $15,000 \mathrm{~g} / \mathrm{m}^{3}$. The 3 -axis accelerometer monitors the frequency and intensity of movement for protocol compliance determination. The nephelometer and accelerometer data can be combined to calculate the potential inhaled dose. For this study, this calculation was performed by RTI experts in the USA.

Quality control metrics continuously monitored are temperature, relative humidity, pressure drop across the filter, battery voltage and sample flow rate. The comparability of MicroPEM PM and accelerometer data to a known "referee" standard defines its accuracy. The MicroPEM achieves the US EPA criteria for $\mathrm{PM}_{2.5}$ and $\mathrm{PM}_{10}$ impactor cut-points, $\pm 0.5 \mu \mathrm{m}$. Collocated laboratory testing has shown the calibration slope is within $\pm 15 \%$ and the intercept is within $\pm 10 \%$ of the standard. The accelerometer standard is the downward $1.0 \mathrm{G}$ value when at rest and the MicroPEM performs within $\pm 5 \%$ of this value. Filter mass and nephelometer mass concentration precision are within $\pm 15 \%$ over the full concentration range. The minimum valid data capture rate, also known as completeness, should exceed $95 \%$ when the MicroPEMs are properly maintained and correctly programmed for sample collection.

After $48 \mathrm{~h}$ sampling, the MicroPEM devices were taken to a central location to undergo filters' change, calibration and flow checking for next use. Measurement data were downloaded using the MicroPEM Docking Station software. The Docking Station is also the interface for calibrating the pump flow, performing nephelometer calibration, programming system cycling and customizing data validity parameters. The data download process retrieves the logged nephelometer, accelerometer, pump flow and other quality control data. Filters from the MicroPEM measurements were sent to RTI in the USA for analysis.

\subsection{CO Monitoring}

CO levels were measured using the Lascar EasyLog USB (https: / www.lascarelectronics. $\mathrm{com}$ /software/ easylog-software/ easylog-usb, accessed on 1 October 2021). This standalone data logger measures and stores up to 32,510 Carbon Monoxide (CO) readings over a 0 to 1000 ppm measurement range and -10 to $+40{ }^{\circ} \mathrm{C}\left(14\right.$ to $\left.+104{ }^{\circ} \mathrm{F}\right)$ operating temperature range. The user can easily set up the logging rate and start time, and download the stored data by plugging the data logger into a PC's USB port and running the purpose designed software. The data can then be graphed, printed and exported to other applications. Data is stored in non-volatile memory and is retained when the battery is empty. In this study, conduction of $\mathrm{CO}$ monitoring was also stationary rather than personal. 


\subsection{Household Survey}

In addition to the above, a household survey was administered at both visits. This assessed housing characteristics (dwelling condition and age) and space heating activity, namely, duration of heating, type of heaters owned and type of heaters used (multiplechoice questions), reasons for differences between heaters owned vs. used (open-ended question), type of fuels used (multiple-choice question) and presence of other respiratory exposures (tobacco smoking indoors and type of smoking products as multiple-choice questions). This questionnaire was designed by the research team and adapted to the local context. At each time point we also kept track of the weather conditions by recording temperature and wind speed, according to the official weather forecast that was issued on the date of each household visit by the national meteorological service.

\subsection{Clinical Outcomes}

Respiratory health outcomes were assessed through an individual questionnaire, which was completed by all adult household members who were in the house during baseline and follow-up visits. This questionnaire was formed by the research team and adapted to the local context, but it also included typical, standardized scales for measuring respiratory symptoms. Data were collected on sociodemographic characteristics (age, gender) and symptoms experienced in general during each of the time points (cough, phlegm, wheezing, breathlessness, the Clinical COPD Questionnaire (CCQ), Medical Research Council (MRC) dyspnea scale). Presence of each symptom was recorded as a yes/no question. The CCQ total score was calculated as the sum of all items divided by ten, with higher value indicating lower health status [25]. The MRC dyspnea scale consists of five items grading a person's perceived breathlessness, with higher grades indicating higher perceived respiratory disability [26]. Similarly, symptoms experienced specifically when the heater was on (cough, phlegm, wheezing, breathlessness, headache, irritated eyes, nasal congestion, running nose, irritated throat, chest tightness, nausea, fatigue, dizziness, irritability), diagnosis of lung diseases (asthma, COPD, tuberculosis, pneumonia, lung cancer) and diagnosis of comorbidities (diabetes, heart disease, stroke, eye disease/cataract) were also recorded. Awareness (knowledge on the harmful effects of biomass burning for adults and children with sources of respective information) was finally added as three closed-ended survey questions as an important health-related outcome.

\subsection{Study Size}

The study size was based on resource considerations, namely the availability of $\mathrm{CO}$ and $\mathrm{PM}_{2.5}$ measuring devices along with the time and costs associated with performing the measurements. Household recruitment and engagement were facilitated by four general practitioners (GPs) serving the targeted population, who identified eligible households from their medical records and performed the initial invitation via a face-to-face or telephone communication. Each GP identified two villages from the catchment area of their practice and invited four eligible households from each village. Subsequently, a convenience sample of 32 households was recruited.

\subsection{Statistical Analysis}

Data were summarized descriptively. Changes between baseline and follow-up measurements were explored using McNemar's tests for categorical variables and Wilcoxon signed rank test for continuous variables. Critical $p$-value was set at the 0.05 level. Analyses were performed using IBM SPSS v23.

\subsection{Ethics}

The study was approved by the 7th Health Region of Crete (Pr. No: 6951). All participants provided signed informed consent prior to their participation. 


\section{Results}

\subsection{Environmental Exposures}

Baseline measurements and household surveys were completed by all 32 identified households. Two households were lost to follow-up due to family issues. The average weather temperature was $14.4{ }^{\circ} \mathrm{C}\left(\min : 12{ }^{\circ} \mathrm{C}\right.$, max: $16^{\circ} \mathrm{C}$ ) at baseline and $14.8{ }^{\circ} \mathrm{C}$ (min: $10{ }^{\circ} \mathrm{C}$, max: $\left.18{ }^{\circ} \mathrm{C}\right)$ at follow-up.

Median (interquartile range, IQR) values of household $\mathrm{PM}_{2.5}$ levels between measurements were $27.4(30) \mu \mathrm{g} / \mathrm{m}^{3}$ at baseline and $27.5(40) \mu \mathrm{g} / \mathrm{m}^{3}$ at follow-up. This difference was not statistically significant $(p=0.607)$. However, these values are above the safe air quality cut-off points ( $25 \mu \mathrm{g} / \mathrm{m}^{3}$ for $24 \mathrm{~h}$ mean) indicated by the WHO [5].

At baseline, the overall median (IQR) value of CO levels was 0.02 (1) parts per million (ppm), while the median of maximal values was 12.3 (32) ppm. At follow-up, the overall median of $\mathrm{CO}$ values was $0.01(0.4) \mathrm{ppm}$ and the median of maximal $\mathrm{CO}$ values was 4.3 (12) ppm. The difference between the overall levels was not statistically significant $(p=0.414)$, in contrast to the difference between the maximal CO values $(p=0.007)$. Still, these $\mathrm{CO}$ levels are below the $\mathrm{WHO}$ air quality guidelines $(26.6 \mathrm{ppm}$ for $1 \mathrm{~h}$ and $6.1 \mathrm{ppm}$ for $24 \mathrm{~h}$ mean) [5].

\subsection{Heating Activity, Fuel Use and Other Respiratory Exposures}

Table 1 presents data on household characteristics, heating activity and air pollution sources between the two assessments. Household questionnaires were collected from all 32 houses at baseline and from 30 houses at follow-up. Dwelling condition was considered good by most households ( $\mathrm{n}=15$ or $48.4 \%$ ), although most were traditional residencies constructed before 1940 ( $\mathrm{n}=21$ or $34.4 \%$ ). The vast majority of households owned local heating devices ( $\mathrm{n}=29$ or $90.6 \%$ ), most of which were stand-alone wood-burning stoves $(\mathrm{n}=17$ or $53.1 \%)$ and fireplaces $(\mathrm{n}=13$ or $40.6 \%)$.

Table 1. Household conditions, heating activity and air pollution sources at baseline and follow-up in rural Crete, Greece.

\begin{tabular}{|c|c|c|}
\hline Outcomes, N (\%) & $\begin{array}{l}\text { Baseline } \\
(\mathrm{N}=32)\end{array}$ & $\begin{array}{l}\text { Follow-Up } \\
\quad(N=30)\end{array}$ \\
\hline \multicolumn{3}{|l|}{ Housing characteristics } \\
\hline \multicolumn{3}{|l|}{ Condition of dwelling } \\
\hline excellent & $5(16.1)$ & \\
\hline good & $15(48.4)$ & \\
\hline average & $9(29)$ & \\
\hline poor & $1(3.2)$ & \\
\hline very poor & $1(3.2)$ & \\
\hline \multicolumn{3}{|l|}{ Year of construction } \\
\hline after 1991 & $3(9.4)$ & \\
\hline 1969-1990 & $8(25.0)$ & \\
\hline 1940-1968 & $6(18.8)$ & \\
\hline before 1939 & $5(15.6)$ & \\
\hline I don't know & $10(31.3)$ & \\
\hline Space heating activity & & \\
\hline Number of months requiring heating, mean $(S D)$ & $5.2(0.9)$ & \\
\hline \multicolumn{3}{|l|}{ What do you have to heat the rooms? } \\
\hline purpose-built heater & $32(100)$ & \\
\hline central heating & $14(43.8)$ & \\
\hline petroleum radiators & $9(28.1)$ & \\
\hline olive cores radiators & $2(6.3)$ & \\
\hline unspecified & $3(9.4)$ & \\
\hline local heating & $29(90.6)$ & \\
\hline
\end{tabular}


Table 1. Cont.

\begin{tabular}{|c|c|c|}
\hline Outcomes, N (\%) & $\begin{array}{l}\text { Baseline } \\
(\mathrm{N}=32)\end{array}$ & $\begin{array}{l}\text { Follow-Up } \\
(\mathrm{N}=30)\end{array}$ \\
\hline stand-alone stoves & $17(53.1)$ & \\
\hline fireplace & $13(40.6)$ & \\
\hline portable electric heater & $5(15.6)$ & \\
\hline air conditioner & $2(6.3)$ & \\
\hline \multicolumn{3}{|l|}{ What do you use to heat the rooms? } \\
\hline purpose-built heater & $31(96.9)$ & $28(93.3)$ \\
\hline central heating & $9(28.1)$ & $1(3.3)$ \\
\hline petroleum radiators & $4(12.5)$ & $0(0)$ \\
\hline olive cores radiators & $2(6.3)$ & $0(0)$ \\
\hline unspecified & $3(9.4)$ & $1(3.3)$ \\
\hline local heating & $28(87.5)$ & $27(90.0)$ \\
\hline stand-alone stoves & $16(50.0)$ & $15(50.0)$ \\
\hline fireplace & $13(40.6)$ & $12(40.0)$ \\
\hline portable electric heater & $4(12.5)$ & $0(0)$ \\
\hline air conditioner & $0(0)$ & $0(0)$ \\
\hline \multicolumn{3}{|c|}{$\begin{array}{l}\text { Reason of difference between what you have and } \\
\text { what you use? }(\overline{N=9)}\end{array}$} \\
\hline financial reasons & $9(100)$ & \\
\hline \multicolumn{3}{|l|}{ Type of fuel for heating } \\
\hline wood & $32(100)$ & $29(96.7)$ \\
\hline petroleum & $8(25.0)$ & $1(3.3)$ \\
\hline olive cores & $3(9.4)$ & $1(3.3)$ \\
\hline electricity & $9(28.1)$ & $0(0)$ \\
\hline \multicolumn{3}{|l|}{ Other exposures } \\
\hline Indoor tobacco smoking (yes) & $10(31.3)$ & $6(20.0)$ \\
\hline \multicolumn{3}{|l|}{ Type of tobacco product } \\
\hline manufactured cigarettes & $10(31.3)$ & $5(16.7)$ \\
\hline rolled cigarettes & $0(0)$ & $1(3.3)$ \\
\hline
\end{tabular}

Non-biomass heaters including petroleum radiators, portable electric devices and air-conditioners were owned by $9(28.1 \%), 5(15.6 \%)$ and $2(6.3 \%)$ houses, respectively. When asked what devices are actually used for heating at baseline, most households still reported using stand-alone stoves ( $\mathrm{n}=16$ or $50 \%$ ) and fireplaces $(\mathrm{n}=13$ or $40.6 \%)$. Petroleum radiators and electric heaters were only used in 4 (12.5\%) households, while none were using the air-conditioner. Among nine households reporting reasons for differences between devices owned versus those used, all were attributed to financial restrictions. At follow-up, trends regarding the use of stand-alone stoves and fireplaces were similar to baseline.

At baseline, all households were using wood as a biomass fuel and, to a lesser extent, olive cores ( $n=3$ or $9.4 \%)$. Petroleum was used by $8(25 \%)$ households and electricity by $9(28.1 \%)$. Wood remained the main fuel used at follow-up ( $n=29$ or $96.7 \%)$, while non-biomass fuels were reported less frequently (petroleum: $n=1$ or $3.3 \%$, electricity: $\mathrm{n}=0)$. Smoking tobacco indoors was reported by $10(31.3 \%)$ households at baseline and $6(20 \%)$ at follow-up. There were no statistically significant differences in PM2.5 and CO levels between households that reported indoor tobacco smoking versus those that did not, either at baseline or follow-up (Supplementary Table S1).

\subsection{Clinical Respiratory Outcomes}

Table 2 presents residents' symptoms and health-related outcomes, in combination with the exposure data described previously. There were 43 adult questionnaires completed at baseline and 42 at follow-up. In total, 33 individuals had paired data for both assessments and are included in the present analysis. Their mean age was 66.8 years $(\mathrm{SD}=14.9)$, while 24 participants $(72.7 \%)$ were women. 
Table 2. Respiratory health-related outcomes in combination with exposure data of residents with paired data in rural households using biomass fuels in Crete, Greece $(\mathrm{N}=33)$.

\begin{tabular}{|c|c|c|c|}
\hline Outcomes N (\%) & Baseline & Follow-Up & $p$-Value * \\
\hline \multicolumn{4}{|l|}{ Socio-demographics } \\
\hline Age (years), mean (SD) & $66.8(14.9)$ & - & - \\
\hline Gender (women) & $24(72.7)$ & - & - \\
\hline \multicolumn{4}{|l|}{ General symptoms } \\
\hline Cough (yes) & $8(24.2)$ & $4(12.1)$ & 0.34 \\
\hline Phlegm (yes) & $9(27.3)$ & $5(15.2)$ & 0.22 \\
\hline Wheezing (yes) & $1(3)$ & $1(3)$ & 1 \\
\hline Breathlessness (yes) & $4(12.1)$ & $4(12.1)$ & 1 \\
\hline MRC dyspnea scale, median (IQR) & $2.0(3)$ & $2.0(1)$ & 0.07 \\
\hline CCQ total score, median (IQR) & $0.2(5)$ & $0.2(10)$ & 0.82 \\
\hline \multicolumn{4}{|l|}{ Symptoms during heating } \\
\hline Cough & $5(15.2)$ & $3(9.1)$ & 0.69 \\
\hline Phlegm & $0(0)$ & $0(0)$ & $\mathrm{N} / \mathrm{A}$ \\
\hline Wheezing & $1(3)$ & $0(0)$ & 1 \\
\hline Breathlessness & $3(9.1)$ & $2(6.1)$ & 1 \\
\hline Headache & $12(36.4)$ & $6(18.2)$ & 0.70 \\
\hline Irritated eyes & $6(18.2)$ & $6(18.2)$ & 1 \\
\hline Nasal congestion & $3(9.1)$ & $1(3)$ & 0.63 \\
\hline Running nose & $2(6.1)$ & $1(3)$ & 1 \\
\hline Irritated throat & $3(9.1)$ & $1(3)$ & 0.5 \\
\hline Chest tightness & $2(6.1)$ & $1(3)$ & 1 \\
\hline Nausea & $6(18.2)$ & $0(0.0)$ & 0.03 \\
\hline Fatigue & $14(42.4)$ & $5(15.2)$ & 0.004 \\
\hline Dizziness & $9(27.3)$ & $1(3)$ & 0.02 \\
\hline Irritability & $8(24.2)$ & $0(0)$ & 0.008 \\
\hline \multicolumn{4}{|l|}{ Exposures } \\
\hline $\mathrm{PM}_{2.5}\left(\mu \mathrm{g} / \mathrm{m}^{3}\right)$, median $(I Q R)$ & $27.4(30)$ & $27.5(40)$ & 0.607 \\
\hline $\mathrm{CO}(\mathrm{ppm})$, median $(I Q R)$ & $0.02(1)$ & $0.01(0.4)$ & 0.414 \\
\hline $\mathrm{CO} \max (\mathrm{ppm})$, median (IQR) & $12.3(32)$ & $4.3(12)$ & 0.007 \\
\hline \multicolumn{4}{|l|}{ Lung health } \\
\hline Asthma (yes) & $0(0)$ & & \\
\hline COPD (yes) & $2(6.1)$ & & \\
\hline Tuberculosis (yes) & $1(3.0)$ & & \\
\hline Pneumonia (yes) & $5(15.2)$ & & \\
\hline Lung cancer (yes) & $0(0)$ & & \\
\hline \multicolumn{4}{|l|}{ Comorbidities } \\
\hline Diabetes (yes) & $9(27.3)$ & & \\
\hline Heart disease (yes) & $12(36.4)$ & & \\
\hline Stroke (yes) & $4(12.1)$ & & \\
\hline Eye disease/cataract (yes) & $11(33.3)$ & & \\
\hline \multicolumn{4}{|l|}{ Awareness } \\
\hline $\begin{array}{l}\text { Did you know that biomass burning } \\
\text { may harm your health? (yes) }\end{array}$ & $16(48.5)$ & & \\
\hline \multicolumn{4}{|l|}{ Source of information } \\
\hline Healthcare professional & $2(12.5)$ & & \\
\hline Physician & $2(12.5)$ & & \\
\hline Media (radio, newspaper, TV) & $12(75.0)$ & & \\
\hline Family & $2(12.5)$ & & \\
\hline Villagers & $0(0)$ & & \\
\hline Own experience & $1(6.3)$ & & \\
\hline $\begin{array}{c}\text { Did you know that biomass burning } \\
\text { may harm your children's health? } \\
\text { (yes) }\end{array}$ & $17(51.5)$ & & \\
\hline
\end{tabular}


The most frequently reported general respiratory symptom at both time points was phlegm ( $n=9$ or $27.3 \%$ vs. $n=5$ or $15.2 \%$ ), followed by cough $(n=8$ or $24.2 \%$ vs. $n=4$ or $12.1 \%$ ). Differences in all general respiratory symptoms including cough, phlegm, wheezing and breathlessness were not significant between assessments.

At baseline, fatigue was the most common symptom experienced specifically when the heater was on $(n=12$ or $42.4 \%)$, followed by headache ( $n=12$ or $36.4 \%)$. At follow-up, the respective symptoms were headache and irritated eyes ( $n=6$ or $18.2 \%$ for both). Among symptoms experienced specifically when the heater was on, nausea, fatigue, dizziness and irritability were reported at significantly higher rates during baseline compared to follow-up ( $\mathrm{n}=6$ or $18.2 \%$ vs. $\mathrm{n}=0, p=0.03 ; \mathrm{n}=14$ or $42.4 \%$ vs. $\mathrm{n}=5$ or $15.2 \%, p=0.004$; $\mathrm{n}=9$ or $27.3 \%$ vs. $\mathrm{n}=1$ or $3 \%, p=0.02$ and $\mathrm{n}=8$ or $24.2 \%$ vs. $\mathrm{n}=0 ; p=0.008$, respectively). The occurrence and frequencies of symptoms reported specifically when the heater was on are in line with the $\mathrm{CO}$ exposure data and contrary to $\mathrm{PM}_{2.5}$ concentrations. However, differences between baseline and follow-up levels are not statistically significant.

No participant reported having asthma. COPD was reported by $2(6.1 \%)$ participants, while $5(15.2 \%)$ reported having experienced pneumonia. Heart disease was the most common comorbidity ( $n=12$ or $36.4 \%$ ), followed by eye disease $(n=11$ or $33.3 \%$ ). There were no meaningful statistically significant differences in the most common symptoms between people with any comorbidities versus without, either at baseline or follow-up (Supplementary Table S2).

Less than half of participants ( $\mathrm{n}=16$ or $48.5 \%$ ) knew that indoor biomass burning for heating could harm their health, of which the majority ( $\mathrm{n}=12$ or $75 \%$ ) had heard so from media, followed by a healthcare professional/physician ( $n=4$ or $25 \%$ ).

\section{Discussion}

\subsection{Summary of Findings and Comparison with the Literature}

To the best of our knowledge, this study is among the first to provide insights about the levels of HAP and relevant health-related practices and outcomes during a period of economic recession in Greece. Our results revealed levels of household $\mathrm{PM}_{2.5}$ exceeding the WHO air quality guidelines. These values are lower than those reported in a similar FRESH AIR study conducted in global low-resource settings [27], and further investigation is warranted to determine whether this can suggest a public health issue in rural Crete. Still, although direct comparisons cannot be performed, a recent study including outdoor data from the second largest Greek city showed that biomass burning during winter comprised the second largest $\mathrm{PM}_{2.5}$ source, indicating an important health-related issue deserving prompt attention [28]. Additionally, another study assessing personal PM exposure through an indoor-outdoor experiment in Athens showed that, in general, 24 hours averaged PM 2.5 concentrations frequently exceeded the limits set by the European Union [29].

Interestingly, although clean fuel devices were owned by a considerable proportion of households in our study, they were used at substantially lower rates, with disparities being attributed to financial limitations. This is in accordance with previous evidence highlighting the negative impact of the economic crisis on heating practices in Greece [16]. In another study exploring indoor environmental conditions in low-income, urban households during the Greek recession, temperatures in participating houses were found to be much lower than the appropriate thresholds for comfort and health, suggesting that the significant barriers to buying energy had placed the population under serious environmental and health-related risks [30].

Cough and phlegm were the most frequent general symptoms, reported by approximately one fourth of participants in both baseline and follow-up measurements. This is in line with the most frequent symptoms recorded in a similar study conducted by members of our group in low-resource settings [27]. In terms of symptoms experienced specifically during heating, we observed an unexpected decline in the frequency of nausea, fatigue, dizziness and irritability at follow-up. This finding could be partially explained by the weather conditions, which were unexpectedly similar and relatively good between the 
two measurements—a fact that may have hindered the true effect of heating practices on respiratory symptoms. Still, this result requires cautious interpretation under the study limitations.

Last but not least, we report on what seems to be an awareness gap for our study population. Namely, less than half of our participants knew that burning biomass inside the household may be harmful for their or their children's health (48.5\% and $51.5 \%$ respectively). For those who knew, the media (including radio, newspaper, TV) was the main source of information $(75 \%)$. This result agrees with previously published literature in low resource settings, where awareness on the respective issue was found at similarly low levels [31].

\subsection{Strengths and Limitations}

The study is prone to certain limitations. Firstly, its descriptive design and small sample does not allow for adequate statistical inference. Moreover, it should not be neglected that the particularities of the local setting and population may differentiate them from Western or other low-resource settings, raising issues of generalizability. Additionally, all provided information was self-reported while different investigators performed the baseline and follow-up evaluations, facts that may have had an impact on the results. The purposive recruitment of households by the facilitating GPs may further introduce bias in terms of selection practices. However, due to the nature of their practice (that also includes household consultations apart from office practice), GPs were able to identify a quite diverse sample in terms of household income and residents' economic and health vulnerability. Still, we did not collect data on residents' educational level, a factor that may influence knowledge regarding smoke and HAP.

Other challenges faced during implementation were related to the function of measuring devices, including recording duration due to fast battery discharge and device calibration. Although these were tackled immediately during field work, there is a chance that they may have affected the measurements' quality.

Furthermore, the presence of a control group of households that do not use biomass fuels would have allowed for more comprehensive comparisons of HAP. However, our primary intention was to reflect on outcomes between periods of diverse biomass use intensity, rather than between "exposed" versus "non-exposed" households. It should, however, not be neglected that the ingress of outdoor pollutants indoors may have influenced our observed measurements, while the lack of data on ventilation may also impact the interpretation of findings. The limited availability of data before the economic crisis does not further allow for the comprehensive interpretation of the observed health outcomes with respect to the noted levels of HAP.

Finally, although we intended to reflect on outcomes between periods of lesser versus extensive heating, weather conditions encountered during the two data collection periods were unusually similar, a fact that may have hampered the identification of meaningful differences.

Still, despite the resource restrictions and the complex nature of data collection, this study is among the first to attempt the measurement of HAP attributed to indoor biomassburning, offering valuable lessons regarding measuring practices and implementation design within the local context.

\subsection{Study Implications and Suggestions for Future Actions}

During the last decade, the economic recession of Greece has meant changes in healthrelated practices, including the switch to biomass burning for domestic heating. The impact of the subsequent indoor air pollution on respiratory health has been studied in several settings (including Greece) and the particular susceptibility of both young children and older adults has been recognised [32,33]. Our study adds to the literature by demonstrating indications that HAP $\left(\mathrm{PM}_{2.5}\right)$ levels exceed the internationally established standards. Although further research is necessary to overcome our study's limitations and confirm our findings, several implications are raised for both healthcare and policy actions. 
As in the case of Greece, HAP is generally linked to poverty. The inability of households to cover their heating needs-described as "fuel poverty" — constitutes a growing problem in Europe. Energy and fuel poverty for low-income households is a complex issue, which has a strong societal and economic aspect. It, thus, demands a multidisciplinary approach for which the strong collaboration and engagement of diverse stakeholders at both the governmental and the international partnerships' level is necessary [8,34]. Understanding local cultural and socio-economic backgrounds and enabling the active involvement of local communities in decision making is, also, crucial for the successful implementation of any intervention aiming to reduce HAP and improve health [35].

Such interventions have been implemented in several countries and their positive effects have been well-documented [36-38]. In a FRESH AIR study with similar aims and methods, a community-oriented intervention of implementing clean cooking/heating stoves was associated with lower exposures and improved short-term health benefits. Local adaptation of the intervention and vigorous inclusion of the community in the selection and installation of clean alternatives was, indeed, central to the success of implementation [27]. In the long-term, experience can also be drawn from other European countries that have developed concrete policies for tackling low-income household problems, including the provision of incentives to improve housing stock, replace heating systems and raise households' energy awareness [39].

The European Fuel Poverty and Energy Efficiency Project [37] has also identified key interventions for fighting energy poverty including the reduction of energy prices and the improvement of energy efficiency of buildings with vulnerable households, the education of households in rational use of energy and the improvement of low incomes. Other proposed actions suggest the implementation of the WHO indoor air quality guidelines on household fuel combustion, the formation of country alliances for the dissemination of improved devices and the investment in renewable energy [40]. Specifically for Greece, discussed strategies include the distribution of natural gas, the development of catalytic domestic wood stoves and the upgrade of buildings' energy efficiency [16,29,41]. Although national action plans integrating the above measures are necessary [42], a European response setting common criteria for energy poverty should be examined for the development of sustainable actions [40].

Last but not least, raising public and professional awareness on HAP is an area deserving special attention when considering interventions for preventing respiratory disease, which, in fact, constitutes the most affordable and effective way to reduce the burden [1]. In a FRESH AIR study conducted in global low-resource settings, the researcher and local stakeholders co-created a train-the-trainer awareness programme empowering communities to take action against biomass and tobacco smoke. They showed significant increases in lung health awareness and the damaging effects of HAP, while the high compatibility of the programme with local contexts was key to its acceptability and eventual success [43].

To close, in our study, general practitioners were central for the information about people, their recruitment and their engagement in the project. For the community to commit to positive action, long-term support from primary care is critical. Primary care is also essential for the effective and equitable combat of respiratory and other non-communicable diseases [31], including cardiovascular disease, for which HAP seems to be holding an emerging role [44]. Trained primary care providers can hold a key role in awareness raising, community motivation and behaviour change with regards to HAP and health [31]. Taking into consideration the Primary Healthcare Reform and the changes in the curriculum of General Practice unfolding in Greece in the last few years [45], this study may serve as a starting-point for exploring organizational issues to strengthen the health system and support local communities in agreement with the agenda of the Sustainable Development Goals [46]. 


\section{Conclusions}

The study described the levels of indoor air pollution and residents' respiratory health characteristics in rural households during the Greek economic crisis. Further research is necessary to overcome our limitations and validate our findings. However, this study could provide baseline information for expanding exposure reduction strategies and enhancing the prevention of both respiratory and other relevant non-communicable diseases.

Supplementary Materials: The following are available online at https:/ / www.mdpi.com/article/10 $.3390 /$ atmos12111369/s1, Table S1: Differences in environmental outcomes between smoking and non-smoking households at baseline and follow-up in Crete, Greece, Table S2: Differences in selected symptoms between people with any comorbidities versus without, at baseline and follow-up in Crete, Greece.

Author Contributions: M.A. participated in local study development, coordinated and contributed to data collection, analysed the data and wrote the first and subsequent versions of the manuscript. I.T. participated in the writing of the original FRESH AIR proposal and provided scientific input for local study development, implementation and results' interpretation. D.S.-P., V.E.C. and A.K. participated in local study development, data collection and results' interpretation. A.B. participated in local study development, coordination of data collection and results' interpretation. N.H.C. was the principal investigator of the overall FRESH AIR project, an original author of the FRESH AIR proposal and contributed to the development of the study protocol. F.v.G. designed the study, trained the local researcher and gave input throughout the data collection, analysis and report. C.L. was the country lead for the FRESH AIR project, providing overall supervision and scientific input for study design, implementation and results' interpretation. All authors have read and agreed to the published version of the manuscript. The FRESH AIR Collaborators participated in the overall FRESH AIR project, contributing to the success of each sub-study.

Funding: As part of FRESH AIR, the study was funded by a research grant from the European Union's Research and Innovation program Horizon2020 (Health, Medical research and the challenge of ageing) under grant agreement no. 680997. The funders had no role in study design, data collection, data analysis, data interpretation or writing of the report.

Institutional Review Board Statement: The study was conducted according to the guidelines of the Declaration of Helsinki, and approved by the Institutional Review Board of the 7th Health Region of Crete (Pr. No: 6951).

Informed Consent Statement: Informed consent was obtained from all subjects involved in the study.

Data Availability Statement: The data presented in this study are available on request from the corresponding author. The data are not publicly available due to data privacy and safety agreement.

Acknowledgments: We sincerely thank Myron Galenianos, team member of the Clinic of Social and Family Medicine, School of Medicine, University of Crete, for his valuable assistance in the implementation of FRESH AIR. We acknowledge Sian Williams, Lisa Cragg and the International Primary Care Respiratory Group (IPCRG) for their continuous support and leadership in the execution of this work. FRESH AIR collaborators: Pham Le An, Azamat Akylbekov, Andy Barton, Pham Duong Uyen Binh, Job FM van Boven, Evelyn Brakema, Dennis Burges, Lucy Cartwright, Liza Cragg, Tran Ngoc Dang, Ilyas Dautov, Berik Emilov, Irene Ferarrio, Ben Hedrick, Le Huynh Thi Cam Hong, Nick Hopkinson, Elvira Isaeva, Rupert Jones, Corina de Jong, Sanne van Kampen, Winceslaus Katagira, Bruce Kirenga, Jesper Kjærgaard, Rianne MJJ van der Kleij, Janwillem Kocks, Le Thi Tuyet Lan, Tran Thanh Duv Linh, Kim Xuan Loan, Maamed Mademilov, Andy McEwen, Patrick Musinguzi, Rebecca Nantanda, Grace Ndeezi, Sophia Papadakis, Hilary Pinnock, Jillian Pooler, Charlotte Poot, Maarten J Postma, Anja Poulsen, Pippa Powell, Nguyen Nhat Quynh, Susanne Reventlow, Sally Singh, Talant Sooronbaev, Jaime Correia de Sousa, James Stout, Marianne Stubbe Østergaard, Aizhamal Tabyshova, Tran Diep Tuan, James Tumwine, Le Thanh Van, Nguyen Nhu Vinh, Simon Walusimbi, Louise Warren, Sian Williams.

Conflicts of Interest: All authors declare no conflict of interest. 


\section{References}

1. Forum of International Respiratory Societies. The Global Impact of Respiratory Disease, 2nd ed.; Forum of International Respiratory Societies: Sheffield, UK, 2017.

2. van Gemert, F.; van der Molen, T.; Jones, R.; Chavannes, N. The impact of asthma and COPD in sub-Saharan Africa. Prim. Care Respir. J. 2011, 20, 240-248. [CrossRef]

3. World Health Organization. Indoor Air Pollution-The Killer in the Kitchen; WHO: Geneva, Switzerland, 2010.

4. World Health Organization. Household Air Pollution and Health; WHO: Geneva, Switzerland, 2018.

5. World Health Organization. WHO Guidelines for Indoor Air Quality: Household Fuel Combustion; WHO: Geneva, Switzerland, 2018.

6. Fullerton, D.G.; Bruce, N.; Gordon, S.B. Indoor air pollution from biomass fuel smoke is a major health concern in the developing world. Trans. R. Soc. Trop. Med. Hyg. 2008, 102, 843-851. [CrossRef]

7. Gordon, S.B.; Bruce, N.G.; Grigg, J.; Hibberd, P.L.; Kurmi, O.P.; Lam, K.B.H.; Mortimer, K.; Asante, K.P.; Balakrishnan, K.; Balmes, J.; et al. Respiratory risks from household air pollution in low and middle income countries. Lancet Respir. Med. 2014, 2, 823-860. [CrossRef]

8. Thurston, G.D.; Kipen, H.; Annesi-Maesano, I.; Balmes, J.; Brook, R.D.; Cromar, K.; De Matteis, S.; Forastiere, F.; Forsberg, B.; Frampton, M.W.; et al. A joint ERS/ATS policy statement: What constitutes an adverse health effect of air pollution? An analytical framework. Eur. Respir. J. 2017, 49, 1600419. [CrossRef]

9. Kurmi, O.P.; Lam, K.B.; Ayres, J.G. Indoor air pollution and the lung in low- and medium-income countries. Eur. Respir. J. 2012, 40, 239-254. [CrossRef]

10. Rennard, S.I.; Drummond, M.B. Early chronic obstructive pulmonary disease: Definition, assessment, and prevention. Lancet 2015, 385, 1778-1788. [CrossRef]

11. World Health Organization. Household Air Pollution: Burden of Disease. 2016. Available online: https://www.who.int/data/ gho/data/themes/air-pollution/household-air-pollution\# (accessed on 28 September 2021).

12. Manoli, E.; Kouras, A.; Karagkiozidou, O.; Argyropoulos, G.; Voutsa, D.; Samara, C. Polycyclic aromatic hydrocarbons (PAHs) at traffic and urban background sites of northern Greece: Source apportionment of ambient PAH levels and PAH-induced lung cancer risk. Environ. Sci. Pollut. Res. Int. 2016, 23, 3556-3568. [CrossRef] [PubMed]

13. Argyropoulos, G.; Besis, A.; Voutsa, D.; Samara, C.; Sowlat, M.H.; Hasheminassab, S.; Sioutas, C. Source apportionment of the redox activity of urban quasi-ultrafine particles (PM0.49) in Thessaloniki following the increased biomass burning due to the economic crisis in Greece. Sci. Total. Environ. 2016, 568, 124-136. [CrossRef] [PubMed]

14. Vouitsis, I.; Amanatidis, S.; Ntziachristos, L.; Kelessis, A.; Petrakakis, M.; Stamos, I.; Mitsakis, E.; Samaras, Z. Daily and seasonal variation of traffic related aerosol pollution in Thessaloniki, Greece, during the financial crisis. Atmos. Environ. 2015, 122, 577-587. [CrossRef]

15. Gratsea, M.; Liakakou, E.; Mihalopoulos, N.; Adamopoulos, A.; Tsilibari, E.; Gerasopoulos, E. The combined effect of reduced fossil fuel consumption and increasing biomass combustion on Athens' air quality, as inferred from long term CO measurements. Sci. Total. Environ. 2017, 592, 115-123. [CrossRef]

16. Saffari, A.; Daher, N.; Samara, C.; Voutsa, D.; Kouras, A.; Manoli, E.; Karagkiozidou, O.; Vlachokostas, C.; Moussiopoulos, N.; Shafer, M.M.; et al. Increased biomass burning due to the economic crisis in Greece and its adverse impact on wintertime air quality in Thessaloniki. Environ. Sci. Technol. 2013, 47, 13313-13320. [CrossRef]

17. Sindosi, O.; Hatzianastassiou, N.; Markozannes, G.; Rizos, E.C.; Ntzani, E.; Bartzokas, A. PM10 Concentrations in a Provincial City of Inland Greece in the Times of Austerity and Their Relationship with Meteorological and Socioeconomic Conditions. Water Air Soil Pollut. 2021, 232, 1-19. [CrossRef]

18. Santamouris, M.; Paravantis, J.A.; Founda, D.; Kolokotsa, D.; Michalakakou, P.; Papadopoulos, A.M.; Kontoulis, N.; Tzavali, A.; Stigka, E.K.; Ioannidis, Z.; et al. Financial crisis and energy consumption: A household survey in Greece. Energy Build. 2013, 65, 477-487. [CrossRef]

19. Amann, M.; Cofala, J.; Klimont, Z.; Nagl, C.; Schieder, W. Measures to address air pollution from small combustion sources. IIASA 2018, 8-10. Available online: https:/ / ec.europa.eu/environment/air/pdf/clean_air_outlook_combustion_sources_report.pdf (accessed on 1 October 2021).

20. Oikonomidou, E.; Anastasiou, F.; Dervas, D.; Patri, F.; Karaklidis, D.; Moustakas, P.; Andreadou, N.; Mantzanas, E.; Merkouris, B. Rural primary care in Greece: Working under limited resources. Int. J. Qual. Health Care 2010, 22, 333-337. [CrossRef]

21. Katsoulakos, N.M.; Kaliampakos, D.C. The energy identity of mountainous areas: The example of Greece. J. Mt. Sci. 2018, 15, 1429-1445. [CrossRef]

22. Tsiligianni, I.G. COPD patients trapped in the financial crisis in rural Crete. Lancet Respir. Med. 2013, 1, e31-e32. [CrossRef]

23. Tsiligianni, I. Respiratory health in Greece. Lancet Respir. Med. 2020, 8, e65-e66. [CrossRef]

24. Cragg, L.; Williams, S.; Chavannes, N.H. FRESH AIR: An implementation research project funded through Horizon 2020 exploring the prevention, diagnosis and treatment of chronic respiratory diseases in low-resource settings. NPJ Prim. Care Respir. Med. 2016, 26, 16035. [CrossRef]

25. van der Molen, T.; Willemse, B.W.; Schokker, S.; ten Hacken, N.H.; Postma, D.S.; Juniper, E.F. Development, validity and responsiveness of the Clinical COPD Questionnaire. Health Qual. Life Out 2003, 1, 13. [CrossRef] 
26. Bestall, J.C.; Paul, E.A.; Garrod, R.; Garnham, R.; Jones, P.W.; Wedzicha, J.A. Usefulness of the Medical Research Council (MRC) dyspnoea scale as a measure of disability in patients with chronic obstructive pulmonary disease. Thorax 1999, 54, 581-586. [CrossRef] [PubMed]

27. van Gemert, F.; de Jong, C.; Kirenga, B.; Musinguzi, P.; Buteme, S.; Sooronbaev, T.; Tabyshova, A.; Emilov, B.; Mademilov, M.; An, P.L.; et al. Effects and acceptability of implementing improved cookstoves and heaters to reduce HAP: A FRESH AIR study. NPJ Prim. Care Respir. Med. 2019, 29, 1-9. [CrossRef]

28. Saraga, D.E.; Tolis, E.I.; Maggos, T.; Vasilakos, C.; Bartzis, J.G. PM2.5 source apportionment for the port city of Thessaloniki, Greece. Sci. Total. Environ. 2019, 650 Pt 2, 2337-2354. [CrossRef]

29. Assimakopoulos, V.D.; Bekiari, T.; Pateraki, S.; Maggos, T.; Stamatis, P.; Nicolopoulou, P.; Assimakopoulos, M. Assessing personal exposure to PM using data from an integrated indoor-outdoor experiment in Athens-Greece. Sci. Total. Environ. 2018, 636, 1303-1320. [CrossRef]

30. Santamouris, M.; Alevizos, S.; Aslanoglou, L.; Mantzios, D.; Milonas, P.; Sarelli, I.; Karatasou, S.; Cartalis, K.; Paravantis, J. Freezing the poor-Indoor environmental quality in low and very low income households during the winter period in Athens. Energy Build. 2014, 70, 61-70. [CrossRef]

31. Brakema, E.A.; van Gemert, F.A.; Williams, S.; Sooronbaev, T.; Emilov, B.; Mademilov, M.; Tabyshova, A.; An, P.L.; Quynh, N.N.; Hong, L.H.T.C.; et al. Implementing a context-driven awareness programme addressing HAP and tobacco: A FRESH AIR study. NPJ Prim. Care Respir. Med. 2020, 30, 42. [CrossRef]

32. Patelarou, E.; Tzanakis, N.; Kelly, F.J. Exposure to indoor pollutants and Wheeze and asthma development during early childhood. Int. J. Environ. Res. Public Health 2015, 12, 3993-4017. [CrossRef]

33. Bentayeb, M.; Norback, D.; Bednarek, M.; Bernard, A.; Cai, G.; Cerrai, S.; Eleftheriou, K.K.; Gratziou, C.; Holst, G.J.; Lavaud, F.; et al. GERIE Study. Indoor air quality, ventilation and respiratory health in elderly residents living in nursing homes in Europe. Eur. Respir. J. 2015, 45, 1228-1238. [CrossRef]

34. Landrigan, P.J.; Fuller, R.; Acosta, N.J.R.; Adeyi, O.; Arnold, R.; Basu, N.; Baldé, A.B.; Bertollini, R.; Bose-O’Reilly, S.; Boufford, J.I.; et al. The Lancet Commission on pollution and health. Lancet 2018, 391, 462-512. [CrossRef]

35. Brakema, E.A.; van der Kleij, R.M.; Vermond, D.; van Gemert, F.A.; Kirenga, B.; Chavannes, N.H. Let's stop dumping cookstoves in local communities. It's time to get implementation right. NPJ Prim. Care Respir. Med. 2020, 30, 1-3. [CrossRef] [PubMed]

36. Thomas, E.; Wickramasinghe, K.; Mendis, S.; Roberts, N.; Foster, C. Improved stove interventions to reduce household air pollution in low and middle income countries: A descriptive systematic review. BMC Public Health 2015, 15, 650. [CrossRef]

37. Quansah, R.; Semple, S.; Ochieng, C.A.; Juvekar, S.; Armah, F.A.; Luginaah, I.; Emina, J. Effectiveness of interventions to reduce household air pollution and/or improve health in homes using solid fuel in low-and-middle income countries: A systematic review and meta-analysis. Environ. Int. 2017, 103, 73-90. [CrossRef] [PubMed]

38. Pope, D.; Bruce, N.; Dherani, M.; Jagoe, K.; Rehfuess, E. Real-life effectiveness of 'improved' stoves and clean fuels in reducing PM2.5 and CO: Systematic review and meta-analysis. Environ. Int. 2017, 101, 7-18. [CrossRef] [PubMed]

39. EU Energy Poverty Observatory. Diagnosis of Causes and Consequences of Fuel Poverty in Belgium, France, Italy, Spain and United Kingdom. 2009. Available online: http://www.powerhouseeurope.eu/uploads/tx_phecasestudies/Analysis_report_ epee_3_2_EN.pdf (accessed on 1 October 2021).

40. Kolokotsa, D.; Santamouris, M. Review of the indoor environmental quality and energy consumption studies for low income households in Europe. Sci. Total. Environ. 2015, 536, 316-330. [CrossRef]

41. Kollias, P.; Kantiranis, N.; Pytharoulis, I.; Zanis, P. Seasonal Variations of the Mineralogical Composition and the Organic Matter Content of Falling Dust in Thessaloniki During 2012-13; Springer: Cham, Switzerland, 2017; pp. 949-956.

42. Brunner, K.M.; Spitzer, M.; Christanell, A. Experiencing fuel poverty. Coping strategies of low-income households in Vienna/Austria. Energy Policy 2012, 49, 53-59. [CrossRef]

43. World Health Organization. 2008-2013 Action Plan for the Global Strategy for the Prevention and Control of Noncommunicable Diseases; WHO: Geneva, Switzerland, 2009.

44. Uzoigwe, J.C.; Prum, T.; Bresnahan, E.; Garelnabi, M. The emerging role of outdoor and indoor air pollution in cardiovascular disease. N. Am. J. Med. Sci. 2013, 5, 445-453.

45. World Health Organization. Greek Health Reform: Opening of New Primary Health Care Units. 2017. Available online: https:/ / www.euro.who.int/en/countries/greece/news/news/2017/12/greek-health-reform-opening-of-new-primaryhealth-care-units (accessed on 28 September 2021).

46. Kieny, M.P.; Bekedam, H.; Dovlo, D.; Fitzgerald, J.; Habicht, J.; Harrison, G.; Kluge, H.; Lin, V.; Menabde, N.; Mirza, Z.; et al. Strengthening health systems for universal health coverage and sustainable development. Bull. World Health Organ. 2017, 95, 537-539. [CrossRef] [PubMed] 